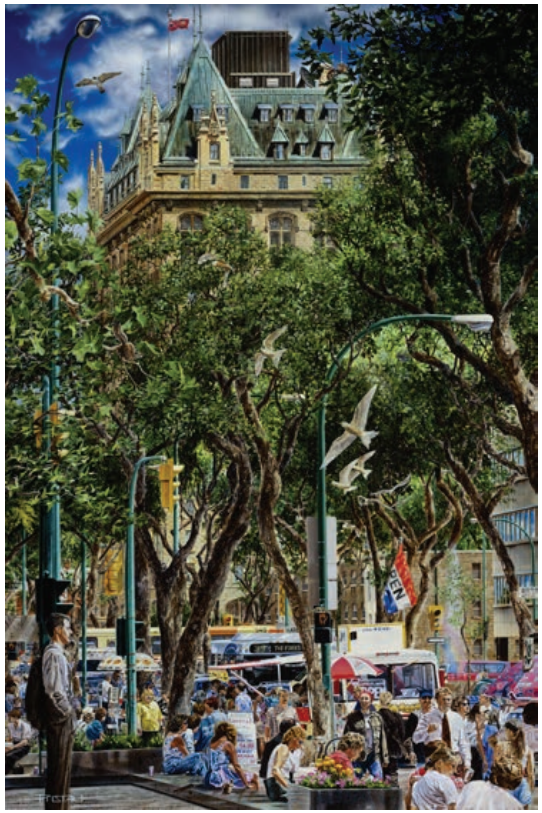

\title{
About the cover art
}

\section{Broadway Vendors}

Broadway Avenue, has a mixture of modern office buildings, residential walk-ups and restaurants that make it one of Winnipeg's most attractive areas. It is famous for its canopy of trees that dates back to an era when most of downtown was devoid of green spaces. As soon as the weather warms up, thousands of office workers join with residents, shoppers and equally numerous squirrels and birds to share the fresh air and hotdogs. At the centre is The Hotel Fort Garry. Built by the Grand Trunk Railway in 1913, it is a former railway hotel in the grand tradition. The steeply pitched roof and multiple dormers, characteristic of the chateau style railway hotel that is unique to Canadian architecture.

\section{David Klaus Ristau}

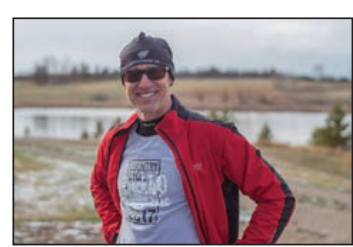

David is an award winning Winnipeg artist who works in a variety of styles and mediums, but is best known for his well researched and meticulous paintings. David's interests are varied and it shows in his work. His experience as a draftsman, railcar repairman, city bus driver, and lifetime resident of Winnipeg are evident in his colourful paintings, charcoal drawings, and panoramas.

David was born in Winnipeg's North End and his interest in art began as a child and has never left him. He completed his BFA, with first class honours, at the University of Manitoba, later in life while working full time. He majored in several areas, including Drawing, Sculpture, and English Literature, before completing his thesis in Graphic Design.

Besides art, David is also an avid athlete, particularly cycling. He often competes in road racing, cyclocross, and mountain biking, but his greatest passion is touring and endurance racing. David has done several long solo expeditions, that culminated in a $12,000 \mathrm{~km}$ tour of Canada from coast-to-coast and everything in between, as well as completing the gruelling Tour Divide mountain bike race from Banff to Mexico. He is also passionate about winter endurance racing, completing 14 consecutive winter ultras in events such as the Arrowhead 135, the Tuscobia 160, and Manitoba's Actif Epica, and is sometimes on the podium in these events. Currently he is writing a novel that is allegorically based on the 12,000 photos he took on his Canada trip, and working on an art project based on the novel.
Having been active in sports throughout his life, David, unfortunately, has had a few accidents and wound up in the Emergency Room a couple times. David recalls some of his experiences with healthcare quite favourably:

While I do not have fond memories of sitting in the Emergency Room, I was often impressed with the care I received once I found myself in a hospital room. A couple hospital stays come to mind. Once when I broke my jaw, many years ago, after it was wired shut, I always had a nurse sit with me for as long as I was in the hospital. They looked out for me, making sure I was comfortable, and I often had to tell them that I was doing fine. Before I was discharged, several nurses came by to say, "Goodbye," which made me feel specially cared for.

On another occasion, just a few years ago, I broke my shoulder in a crash. Two months later, just as the shoulder was getting better, I took a couple pills I was prescribed for a skin rash, which caused my liver to shut down. Again, I was back in Emergency for a couple days. The doctors came through one after another, but no one could figure out what was wrong with me, or advise me as to whether I would fully recover. I was rather depressed at how that summer was going, but again the nurses would come around often to check on me, and stay and chat to cheer me up whenever they had time. When my liver started functioning normally again and I was to be discharged, again many of them came around again to say, "Goodbye." It always made such a difference in a depressing situation when I felt cared for.

I also have to mention the wonderful care my mother received when she was dying. Naturally, everyone in the family was very distressed at watching her decline, but we always knew that she was attentively watched over. 